\title{
MUDANÇA ESTRUTURAL E CRESCIMENTO DOS MUNICÍPIOS FLUMINENSES: UMA ANÁLISE DA MOBILIDADE RELATIVA NO PERÍODO 1998-2008
}

\author{
Eva Yamila da Silva Catela *
}

\begin{abstract}
Resumo
O presente artigo investiga a dinâmica econômica dos municípios fluminenses e a influência da estrutura produtiva sobre esta dinâmica. Após a estimação de estratos de renda e de salário médio, foram calculadas as intensidades de transição entre os diferentes estratos encontrados. Os resultados indicam uma maior mobilidade dos municípios quando considerado o rendimento médio do trabalho que quando considerada a renda per capita. Além disso, percebe-se que o tipo de estrutura produtiva que o município apresenta tem marcada influência na permanência e na mobilidade entre tais estratos. Em especial, a especialização em setores industriais, assim como o grau de diversificação da estrutura produtiva tem forte influência positiva para explicar a probabilidade de transitar a estratos superiores de renda e de salário médio.
\end{abstract}

Palavras-chave: Municípios de Rio de Janeiro; Estrutura produtiva; Crescimento; Mobilidade.

\begin{abstract}
This paper is aimed at the investigation of economic dynamics of the cities of Rio de Janeiro State and the consequences of production structure. After estimating income and average wages strata, the intensities of tansitions between different strata were calculated. The results show a greater mobility of cities when considering average income of workers than when considering per capita income. Moreover, it is clear that the type of production structure of the city has a marked influence on the permanence and mobility between these strata. In particular, the specialization in industrial sectors and the degree of diversification of the productive structure have a strong positive influence to explain the probability of moving to the upper strata of income and average wage.
\end{abstract}

Keywords: Rio de Janeiro cities; Productive structure; Growth; Mobility. JEL classification: R11, R15, C33

\footnotetext{
* Professora de na Universidade Federal de Santa Catarina. E-mail:eva@cse.ufsc.br
} 


\section{Introdução}

O processo de crescimento recente do estado do Rio de Janeiro apresenta uma vasta diversidade de resultados entre os diferentes municípios, seja no que se refere ao desempenho dos diferentes setores analisados (dentro da agricultura, indústria extrativa, indústria de transformação e serviços) ou quando considerados os resultados de evolução do PIB e dos salários intraestado.

O presente trabalho tem um duplo objetivo. Em primeiro lugar, analisar a evolução do crescimento da renda e dos salários dos trabalhadores dos municípios fluminenses nas duas últimas décadas, tomando-se, como hipótese fundamental, a existência de ampla heterogeneidade nesse processo entre os diferentes municípios. Tal heterogeneidade aparece em várias dimensões: quanto à concentração de renda, em 1996 os três maiores municípios (Rio de Janeiro, ${ }^{1}$ Niterói e Duque de Caxias) concentravam 75\% da renda e em 2008, os três maiores (Rio de Janeiro, Duque de Caxias e Campo dos Goytacazes) concentravam $62 \%$ da renda estadual; quanto às disparidades no crescimento do PIB ao longo das últimas duas décadas para os distintos municípios fluminenses; e quanto ao tamanho relativo de cada município.

O segundo objetivo consiste em relacionar essa evolução heterogênea a variáveis associadas ao padrão da estrutura produtiva e suas mudanças, considerando medidas que caracterizam o município em relação à existência de especialização produtiva, setor de especialização (produtos primários, indústria extrativa, indústria de transformação) e existência de indústria diversificada. Dados do TCE-RJ (2009) mostram uma dinâmica díspar nos resultados dos diferentes setores produtivos no ano de 2000 no Rio de Janeiro, com um forte avanço da indústria extrativa (basicamente petróleo), resultados modestos na construção civil e serviços públicos, e um estancamento da indústria de transformação. A hipótese central deste trabalho é que tal mudança estrutural tenha uma correlação com a evolução da distribuição de renda, assim como as disparidades salariais entre os municípios do Estado.

Dados esses objetivos, será empregado um procedimento de dois estágios. Em primeiro lugar, a partir da metodologia de cluster $k$-means, identificamse grupos ou estratos de municípios em que a renda e o salário médio são marcadamente diferentes no período considerado e se analisa o processo de transição entre os grupos a partir da análise de matrizes de um modelo multiestado. O referido método para realizar a análise de dinâmica da renda no Brasil foi utilizado por Catela et al. (2010) e por Magalhães \& Miranda (2009). Em segundo lugar, com base em modelos de regressão probit ordenado, são parametrizadas as transições entre estratos com variáveis associadas à estrutura produtiva da cidade. Entende-se que esse exame da transição e seus determinantes sejam fundamentais, já que ela permite identificar variáveis que contribuem para a superação das disparidades no tempo. das:

As hipóteses que norteiam a presente pesquisa podem ser assim resumi-

a) Os municípios fluminenses apresentam heterogeneidade em termos da renda per capita, assim como de salários, caracterizada pela existência de estratos diferenciados.

\footnotetext{
${ }^{1}$ Cabe destacar que o município do Rio de Janeiro concentra quase $50 \%$ da renda estadual
} 
b) As probabilidades de transição entre tais estratos são não homogêneas, isto é, a "força de transição" é diferente para os diferentes estratos de renda. Isso implica que, em alguns casos, é mais fácil que os municípios progridam (ou caiam) na direção de estratos de maior (menor) renda.

c) As variáveis associadas à estrutura produtiva e ao capital humano influenciam as intensidades de transição entre estratos de forma diferenciada. Essas variáveis são: (i) grau de especialização produtiva do município; (ii) grau de diversificação produtiva do município; (iii) inserção no mercado externo; (iv) grau de participação nas regalias do petróleo; (v) escolaridade; (vi) região geográfica.

O presente trabalho é organizado em cinco seções além desta introdução. Na seção 2, é revisitada a literatura que trata da problemática do crescimento divergente e o desenvolvimento regional associado ao padrão produtivo. $\mathrm{Na}$ seção 3, são apresentados os dados utilizados nesta pesquisa, bem como a metodologia. Na seção 4, são exibidos os resultados, divididos em duas partes: agrupamento de municípios e determinantes das transições entre estados. Por fim, na seção 5 é apresentada a conclusão com os comentários finais.

\section{As teorias de crescimento econômico, a desigualdade regional e as aglomerações produtivas.}

O reconhecimento da importância do espaço na conformação dos padrões de desigualdade espacial e na dinâmica de renda regional surge dentro da economia com a questão da convergência de renda. Nesses modelos, cujo marco fundamental é o modelo de Solow (1956), a taxa de crescimento da renda per capita é inversamente relacionada com seu nível inicial, dada a hipótese de retornos decrescentes do capital. Como consequência, haverá convergência absoluta e as economias pobres tendem a crescer mais rápido do que as economias ricas, visto que as economias pobres em capital (e em renda) terão uma maior produtividade marginal do capital.

Esse resultado contrasta com as implicações da primeira geração de modelos de crescimento endógeno, como o de Romer (1986) e Lucas (1988). O ponto-chave desses modelos é a existência de rendimentos crescentes de escala para o conjunto de fatores de produção acumuláveis (incluindo dentro do capital o capital humano) que levam à inexistência de convergência.

No início da década de noventa, distintos autores (Barro \& Sala-I-Martin 1990, 1992, Mankiw et al. 1992) utilizaram uma nova definição de convergência, denominada convergência condicional, para demonstrar que o modelo neoclássico é consistente com a evidência empírica. Os citados economistas argumentaram que o modelo neoclássico estabelecia que, se parâmetros tecnológicos, de preferências, ou institucionais, diferem entre dois países, estes possuem estados estacionários diferentes.

Quah (1993) critica as análises da dinâmica de crescimento baseadas no modelo neoclássico, mostrando que o conceito de convergência é uma proposição acerca da dispersão da distribuição de renda (e da taxa de crescimento) entre países e um resultado negativo da regressão do nível inicial de renda não implica necessariamente uma redução nessa dispersão, podendo estar indicando apenas uma regressão para a média, ignorando os movimentos intra- 
distribuição e mudanças de posição no ranking de renda per capita entre os países.

No final da década de noventa, a importância das externalidades espaciais, as interações de regiões e cidades, e as não linearidades, contribuíram crescentemente para explicar as desigualdades regionais, dentro da nova geografia econômica (Puga 2010, Fujita et al. 2001), da teoria do crescimento endógeno (Aghion \& Howitt 1997), e da teoria de não linearidade do processo de crescimento e desigualdade (Durlauf \& Johnson 1995, Quah 1997).

Para o Brasil, vários estudos têm focado na verificação da existência de convergência, dos quais alguns apontam a falta de convergência absoluta entre os municípios. Azzoni et al. (2004), a partir de dados da Pesquisa Nacional por Amostra de Domicílios (PNAD) para 19 estados no período 1981-1996, chegaram à conclusão de que as rendas per capita convergem apenas em nível condicional e que as atuais diferenças de renda permanecerão inalteradas em razão de diferenças geográficas e no nível de educação dos estados objeto de estudo.

Outros estudos, como os de Laurini et al. (2003), Andrade et al. (2004) e Gondim \& Barreto (2004), empregam a análise da dinâmica da distribuição de renda e, baseando-se no surgimento de duas modas nessa distribuição, concluem que existem dois clubes no longo prazo dentro dos municípios brasileiros: o primeiro de baixa renda, formado essencialmente pelos municípios das regiões Norte e Nordeste, e outro de alta renda, composto por municípios das regiões Centro-Oeste, Sudeste e Sul.

Magalhães \& Miranda (2009) estimam matrizes de transição de Markov para revelar a dinâmica de distribuição da renda per capita, a taxa de alfabetização e os anos de estudo nos municípios brasileiros. Os resultados indicam um forte processo de divergência na renda e de convergência nas outras variáveis.

Do discutido, salienta-se a importância de utilizar métodos paramétricos e não paramétricos que considerem a existência de grupos de renda diferenciados e evoluções divergentes dentro e entre tais grupos, no estudo dos municípios fluminenses. Outra questão é, depois de exibir outras dimensões do processo de desenvolvimento regional, a exibição, na seção 3 , da metodologia de pesquisa utilizada.

Diferentes autores dentro da teoria dos sistemas urbanos apresentam as cidades como o resultado do equilíbrio entre duas forças: a aglomeração e a dispersão. A primeira cria benefícios para que indivíduos e empresas se localizem perto uns dos outros. Já a força da dispersão aparece porque existem custos associados à aglomeração (Henderson 1974, Rivera-Batiz 1988, AbdelRahmany \& Fujita 2006, Fujita 1999, Krugman 1991, Anas \& Xiong 2003). Se a primeira dessas forças outorga racionalidade à existência das cidades, a segunda limita o seu tamanho. O tamanho ótimo de uma cidade será dado pelo resultado desse conflito entre economias de localização que atuam como força aglutinadora e a densidade urbana que tende a dispersar a amálgama de indivíduos e firmas.

Pode-se citar dois tipos de aglomeração que geram externalidades positivas na aglomeração urbana. A primeira é a externalidade de localização, chamada de externalidade Marshall-Arrow-Romer (Abdel-Rahmany \& Anas 2004), que resulta de transbordamentos de conhecimentos dentro das indústrias do mesmo setor produtivo ou de setores complementares. A segunda é a externalidade de urbanização, também chamada como Jacobs-Porter, que 
é ocasionada pela transferência de conhecimentos entre indústrias não correlatas. Neste último caso, enfatiza-se a importância da diversidade para o aumento da produtividade, eficiência e competitividade das cidades e, assim, para o crescimento de um país. Evidências empíricas de autores como Quigley (1998) sugerem que os ganhos de eficiência como consequência da heterogeneidade produtiva são não triviais.

Vários autores conduziram estudos empíricos procurando identificar o impacto que as economias de aglomeração têm sobre a produtividade e o crescimento econômico. Henderson (1986) mede a diversificação pelo emprego total na cidade e a especialização pelo emprego em um setor particular. A partir desses dados, considera o impacto da especialização e diversificação sobre a produtividade para dois países, Estados Unidos e Brasil, apontando evidências do impacto das economias de especialização e nenhuma evidência do impacto das economias de diversificação.

Em outro trabalho, Henderson et al. (1995) analisam o impacto da especialização sobre o crescimento, para indústrias classificadas como maduras e para indústrias de alta tecnologia. Para as indústrias de alta tecnologia, encontram que a especialização não tem um efeito positivo sobre o crescimento. Já para as indústrias maduras, constataram que o efeito é positivo e significativo.

Utilizando outra medida para estudar a diversidade, Rosenthal \& Strange (2003) descobrem que a diversidade influi sobre a criação de novas empresas. Wheaton \& Lewis (2002), por sua vez, identificam um bônus de salário nas cidades que apresentam maior especialização relativa, isto é, maior concentração do fator trabalho em determinado setor produtivo.

Para o Brasil, dois trabalhos recentes merecem destaque. Em primeiro lugar, Galinari et al. (2007), que pesquisam se as economias de aglomeração se encontram presentes no contexto urbano do Brasil e se influenciam os salários industriais. Os autores constataram que, se a década de noventa foi caracterizada por profundas mudanças institucionais, isso não foi suficiente para homogeneizar os salários dentro do país entre as suas regiões.

Em segundo lugar, o trabalho de Catela et al. (2010) testa empiricamente a relação entre indicadores de especialização e diversificação industrial e uma medida de produtividade (salário médio do trabalhador), para conhecer o efeito das economias de aglomeração sobre o desenvolvimento das cidades brasileiras, utilizando um modelo de misturas finitas. Os resultados mostram que a dualidade norte-nordeste/sul-sudeste, largamente estudada em outras pesquisas, é confirmada. No entanto, algumas cidades não se inserem na mesma dinâmica da região a que pertencem.

\section{Estratégia empírica da pesquisa e dados}

\subsection{Estratégia Empírica}

O objetivo empírico da pesquisa pode ser dividido em três partes. Primeira, a análise da evolução do crescimento dos municípios implica: a) agrupar as unidades de estudo de acordo com o nível de renda, utilizando primeiro o PIB per capita e depois o salário médio; b) a partir desses grupos, estudar a dinâmica de transição relacionada à estrutura produtiva.

O primeiro modelo utilizado é de regimes múltiplos, que conformam uma importante ferramenta estatística para a análise de dados longitudinais, utilizados para descrever sucessivas mudanças ou transições de estados expe- 
rimentados por unidades amostrais. Tais modelos são definidos a partir de um processo estocástico no qual, a qualquer instante do tempo, uma unidade ocupa um estado definido em um espaço de estados convenientemente construído. A informação acerca da progressão do fenômeno estudado registra a mudança temporal da variável de interesse. A seguir, determinar a probabilidade de transição associada com cada uma destas mudanças é relevante para entender e identificar que fatores se relacionam com a transição de uma unidade em particular (municípios) através de diferentes estratos (níveis de renda ou salário médio).

Um problema que surge previamente é que o modelo requer uma especificação do número de regimes e as transições das unidades estudadas entre esses regimes ao longo do período utilizado. Propõe-se a utilização do instrumental de cluster $k$-means que possibilita conhecer o número de componentes (estratos) dentro de uma distribuição, bem como as médias e as variâncias dos referidos estratos. A escolha do método justifica-se pos os grupos ou estratos de renda de municípios são construídos endogenamente, considerando a diversidade de processos estocásticos que as observações apresentam, sem necessidade de realizar agrupações arbitrárias ad hoc. O segundo objetivo empírico é mostrar que a probabilidade de permanecer e se mobilizar entre estratos depende de certas variáveis relacionadas à estrutura produtiva da cidade. Nesse sentido, o modelo probit ordenado visa encontrar a probabilidade de que os municípios que se encontrem em determinados estratos de renda, considerando a variável dependente categórica, isto é, cai em diferentes categorias mutuamente excludentes (níveis de renda ou salário médio) e estas categorias encontram-se ordenadas (de menor a maior).

No Anexo 3, esses distintos métodos são abordados e explicados.

\subsection{Descrição dos Dados}

O estado do Rio de Janeiro conta com 92 municípios, agrupados em seis mesorregiões: Baixadas Litorâneas, Centro Fluminense, Metropolitana do Rio de Janeiro, Noroeste Fluminense e Norte Fluminense.

O trabalho utiliza, como base de dados principal, a Relação Anual de Informações Sociais do Ministério do Trabalho e Emprego (RAIS/MTE), que possui informações disponíveis para todo o país sobre o estabelecimento empregador, assim como sobre os empregados, a partir dos vínculos empregatícios formalizados em um determinado ano-base.

A base de dados da RAIS/MTE tem como principal vantagem uma elevada desagregação setorial e geográfica das informações, o que torna possível obter e processar dados desagregados, até o nível de municípios, bem como até três dígitos em termos setoriais. Além disso, a RAIS apresenta um grau relativamente elevado de uniformidade, permitindo comparar a distribuição dos setores da atividade econômica ao longo do tempo.

As vantagens são contrabalançadas por algumas deficiências. A primeira deficiência da RAIS é sua cobertura, que inclui apenas relações contratuais formalizadas, omitindo a parcela dos trabalhadores não formais, o que introduz um viés importante referente ao mercado de trabalho real. Uma segunda deficiência da RAIS decorre da utilização do método de autoclassificação das próprias firmas na coleta das informações primárias, que pode ter efeitos importantes nos casos de empresas multiplanas que declarem todo o volume de emprego na mesma unidade produtiva, geralmente na matriz, e de empre- 
sas multiprodutos que declarem enquadrar-se apenas na atividade correspondente ao seu produto principal.

A última deficiência diz respeito ao fato de a RAIS ser declaratória, o que pode provocar distorções na análise de pequenas empresas ou de regiões menos desenvolvidas, já que nessas regiões é mais elevada a ocorrência de empresas não declarantes, como também no caso de empresas pequenas.

Foram utilizados os dados de empregos da RAIS/MTE do período 19962010. O universo de análise, convergente com a proposta do trabalho e as características da base de dados da RAIS, foi delimitado em dois níveis diferentes. Do ponto de vista geográfico, foram utilizados todos os municípios fluminenses. Do ponto de vista da atividade econômica, foi utilizada uma desagregação setorial que considera os setores primários, indústria extrativa e indústria de transformação dois dígitos da CNAE/95 (para os anos 2000 até 2004) e CNAE 2.0 (de 2006 até 2010). Da RAIS foram extraídos diversos dados, listados a seguir.

Em primeiro lugar, o estoque de trabalhadores (número de empregos), nas categorias desagregadas no nível municipal, por tipo de atividades econômicas (dois dígitos da Classificação Nacional da Atividade Econômica - CNAE). A partir desses dados, foram construídos os indicadores para analisar a especialização e a diversidade da indústria de cada uma das cidades do estado.

Como medida de aglomeração, foram construídos os diferentes índices. Em primeiro lugar, o quociente locacional (QL), já usado na medição de aglomerações no Brasil em diversos estudos (Britto \& Albuquerque 2002, Crocco et al. 2006), O QL compara duas estruturas setoriais-espaciais: no numerador tem-se o município em estudo e no denominador, uma economia de referência, que é, no nosso caso, o estado do Rio de Janeiro. Desta forma, tem-se: ${ }^{2}$

$$
Q L=\frac{\left(\frac{E_{j}^{i}}{E_{j}}\right)}{\left(\frac{E_{R I}^{i}}{E_{R I}}\right)}
$$

em que:

- $E_{j}^{i}$,total de empregados da atividade i no municï ¿œpio j;

- $E_{j}$, total de empregados no município j;

- $E_{R J}^{i}$,total de empregados da atividade i no estado do RJ;

- $E_{R J}$, total de empregados no estado do RJ.

Uma medida comum em relação à diversidade é o índice Herfindahl-Hirschman inverso, que se obtém pela razão entre um e a somatória do quadrado da porção de cada setor no emprego local. A medida é corrigida em virtude das diferenças nas participações no emprego setorial da cidade e do estado. Assim, define-se o índice de diversificação relativa como:

$$
I D R_{i}=\frac{1}{\sum_{j}\left|E_{i j}-E_{i R J}\right|}
$$

\footnotetext{
${ }^{2}$ Para uma completa revisão dos diferentes índices utilizados para medir aglomeração espacial no Brasil, veja-se Crocco et al. (2006)
} 
O índice de diversificação relativa (idr) será maior quando a composição de atividades na cidade estudada for reflitada no padrão de diversidade da economia estadual.

Da forma em que são medidos, especialização e diversificação não são exatamente opostas e uma cidade pode ser considerada especializada em um setor e ainda contar com uma estrutura produtiva diversificada.

Em segundo lugar, obtiveram-se da RAIS as informações sobre renda média do trabalhador a partir do estoque de salários mínimos das cidades e do número de trabalhadores de cada cidade. Com base nestes dados, é calculado o salário médio de cada uma das cidades estudadas, utilizando os dados de salário mínimo real do Departamento Intersindical de Estatística e Estudos Socioeconômicos (DIEESE).

Em terceiro lugar, obtiveram-se os dados de educação, que correspondem ao estoque de trabalhadores com ensino fundamental, médio e superior como percentagem do total dos trabalhadores da cidade.

Os dados referentes ao PIB per capita, exportações por município e distância da cidade à capital do estado para os diferentes municípios são do Ipeadata regional. Os dados de população são do IBGE( Instituto Brasileiro de Geografia e Estatística). ${ }^{3}$

Os dados de royalties do petróleo, corrigidos pelo INPC, são da Universidade Cândido Mendes (UCAM). ${ }^{4}$ Há duas formas principais de participações governamentais associadas à produção de petróleo e gás no Brasil, os royalties e as participações especiais.

A Tabela 1 apresenta as estatísticas descritivas das variáveis listadas acima. A variável rendimento médio real do trabalho mostra uma dispersão muito menor que o PIB per capita, como pode ser visto a partir do desvio padrão.

A seguir, tem-se os resultados das estimações realizadas.

\section{Resultados}

O primeiro passo da estratégia empírica é estratificar os municípios por níveis de renda per capita, assim como por salário médio recebido pelos trabalhadores. A estratificação ou agrupamento se faz necessária para posteriormente analisar a dinâmica transacional das cidades fluminenses entre tais estratos ou grupos, como também determinar os condicionantes dessa transição. Apresentam-se, a seguir, os resultados dos referidos agrupamentos.

\subsection{Agrupamento por PIB per capita}

Em primeiro lugar, foi realizado o agrupamento, utilizando como variável o PIB per capita, para analisar a conformação dos grupos para todos os municípios ao longo do período $1996-2008 .{ }^{5}$ Os resultados para os anos polares estão na Tabela 2. No anexo 2, encontram-se todos os municípios por grupo de renda.

\footnotetext{
${ }^{3}$ Os dados utilizados podem ser acessados em www. ipeadata.gov.br e em www.ibge. gov.br/home/estatistica/populacao/.

${ }^{4}$ Podem ser acessados em http: / / inforoyalties.ucam-campos.br /

${ }^{5}$ Foram realizados agrupamentos para os anos 1996, 1998, 2000, 2002, 2004, 2006, 2008. Dessa forma, tem-se 7 observações para cada cidade para realizar a análise transacional.
} 
Tabela 1: Estatísticas descritivas

\begin{tabular}{|c|c|c|c|c|}
\hline Variável & Descrição & $\mathrm{N}$ & Média & Desvio Padrão \\
\hline RMeR & $\begin{array}{l}\text { Rendimento do trabalho mé- } \\
\text { dio real para cada município }\end{array}$ & 723 & 649,11 & 348,03 \\
\hline PIBpc & $\begin{array}{l}\text { Produto interno bruto per ca- } \\
\text { pita real para cada município }\end{array}$ & 631 & 8111,63 & 10613,76 \\
\hline Cluster PIB & $\begin{array}{l}1=\text { renda baixa; } 2=\text { renda } \\
\text { média; } 3=\text { renda média-alta; } \\
4=\text { renda alta }\end{array}$ & 609 & 71,51 & 0,81 \\
\hline Cluster Rendimento & $\begin{array}{l}1=\text { rend. baixíssimo; } 2=\text { rend. } \\
\text { baixo; } 3=\text { rend. médio; } 4=\text { rend. } \\
\text { médio-alto; } 5=\text { rend. alto }\end{array}$ & 723 & 2,31 & 1,12 \\
\hline QL & $\begin{array}{l}\text { Quociente locacional (medida } \\
\text { de especialização) }\end{array}$ & 723 & 14,08 & 35,75 \\
\hline IDR & $\begin{array}{l}\text { Índice de Diversificação Rela- } \\
\text { tiva }\end{array}$ & 723 & 0,91 & 0,35 \\
\hline DCap & $\begin{array}{l}\text { Distância do município à capi- } \\
\text { tal do estado }\end{array}$ & 736 & 116,1 & 69,17 \\
\hline Exppc & $\begin{array}{l}\text { Exportações reais per capita } \\
\text { do município }\end{array}$ & 640 & 625,4 & 3290,23 \\
\hline Edu-sup & $\begin{array}{l}\text { Percentual de trabalhadores } \\
\text { do município com educação } \\
\text { superior }\end{array}$ & 723 & 0,1 & 0,05 \\
\hline Royalties & $\begin{array}{l}\text { Royalties + Participações Es- } \\
\text { peciais Anuais em Valores Re- } \\
\text { ais Per capita (corrigidos pelo } \\
\text { INPC) }\end{array}$ & 609 & 448,77 & 1016,57 \\
\hline
\end{tabular}

Fonte: Elaboração própria. Dados extraídos do IBGE, Ipeadata, RAIS, UCAM.

As estimações do cluster $k$-means indicam a conformação de quatro grupos nos anos que conformam o período de 1996 a 2008, com base nos resultados do critério de Calinski-Harabasz. ${ }^{6}$ Considerando as médias de renda per capita, chamamos estes grupos de: Renda Baixa, Renda Média, Renda Médiaalta e Renda Alta.

Em relação aos componentes de cada grupo, comparando o primeiro e o último ano analisado, percebe-se um forte aumento do número de municípios no grupo de renda baixa e uma queda da frequência dos grupos intermediários, de renda média e média alta. O grupo de renda alta mantém a sua frequência representada por dois municípios.

Na Figura 1, percebe-se o aumento da disparidade entre a renda média do primeiro grupo em relação aos outros, e muito especialmente ao grupo de renda alta.

O aumento do número de municípios no grupo de renda baixa aponta uma situação de convergência negativa, dado que dezesseis municípios passam dos grupos de renda média para o grupo de renda baixa. Essa situação é resultado da migração de municípios, alguns dos quais, mesmo tendo um aumento do PIB per capita, não conseguem se sustentar nos grupos de renda média e renda média-alta que apresentaram um forte aumento da renda per capita ao longo do período analisado. Aparecem dentro do grupo de municípios que aumentam o PIB, mas não conseguem sustentar a posição e caem ao primeiro estrato, como, por exemplo, Arraial do Cabo, Arreal, Bom Jardim, Cantagalo,

\footnotetext{
${ }^{6}$ Nos anos 2002 e 2004, o critério indica como número ótimo três grupos, para os demais anos analisados o critério $\mathrm{CH}$ estabelece quatro como número ótimo de grupos.
} 


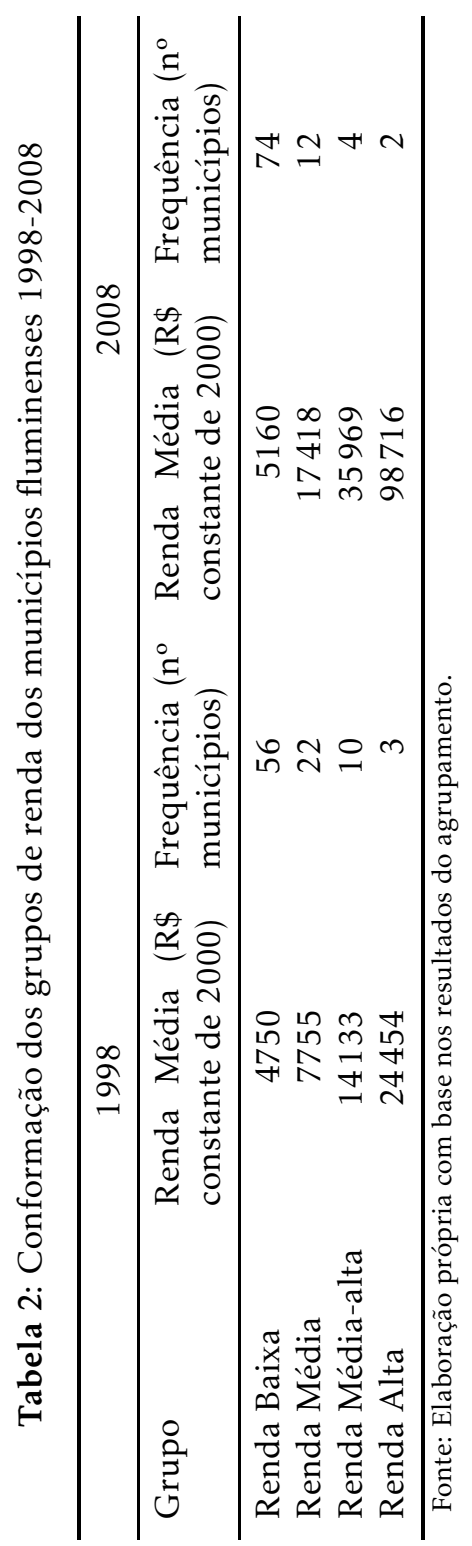


Cardoso Moreira, Comendador Levy Gasparian, Duas Barras, Miguel Pereira, Mangaratiba, Parati, Sapucaia e Sumidouro.

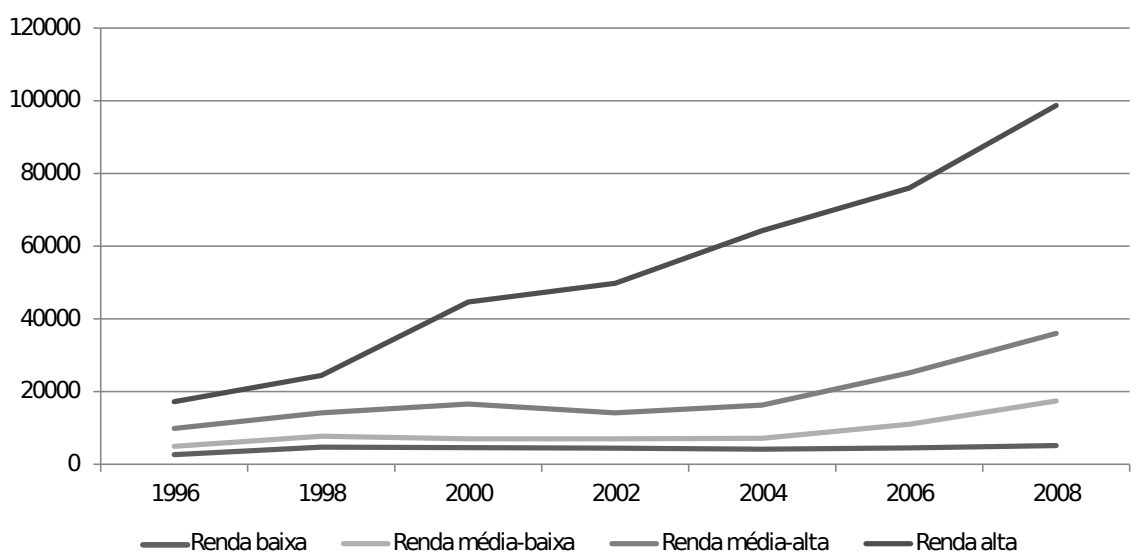

Fonte: Elaboração própria com base nos resultados do agrupamento

Figura 1: Renda média dos grupos de municípios 2000-2008

Os resultados do agrupamento permitem delimitar as características dos grupos da seguinte forma:

a) Tem-se um grupo fortemente predominante de municípios de baixa renda que apresenta um baixíssimo dinamismo em duas dimensões. Em primeiro lugar, o núcleo de municípios que formam o grupo se mantém no período analisado. Trata-se de 48 municípios que representam $30 \%$ da população do estado do Rio de Janeiro. Novos municípios incorporamse no grupo, tornando-o mais forte no período analisado. A segunda dimensão que mostra estancamento é a renda média per capita desse grupo, que se mantém em torno de $\mathrm{R} \$ 4500$ (constantes de 2000) em todo o período.

b) O segundo grupo apresenta um menor número de municípios e um comportamento similar - quanto ao estancamento da renda média ao grupo de renda baixa, até 2004. Nos últimos anos do período analisado, a renda média aumenta fortemente, excluindo municípios que não conseguem seguir a tendência do grupo. Trata-se basicamente de um grupo de transição, que alimenta e é alimentado pelos grupos vizinhos. Salienta-se a presença de Angra dos Reis, Cabo Frio, Duque de Caxias, Itaguaí, Piraí e Resende. O caso da capital, Rio de Janeiro, Volta Redonda e Macaé é similar: as três cidades formam parte do estrato quatro no início do período (1996) e caem progressivamente até o estrato dois no final.

c) No grupo de renda média-alta, a renda real per capita dobra ao longo do período analisado e o número de municípios cai fortemente de dez para quatro municípios. A tendência de aumento da renda é similar ao grupo anterior: um estancamento entre 1998 e 2004 e um forte aumento até 2008. Os municípios que o compõem ao final do período são: Armação de Búzios, Rio das Ostras, Campos dos Goytacazes e São João da Barra. 
d) O grupo de alta renda é composto por dois municípios: Quissamã, ${ }^{7}$ que se mantém nesta posição desde 2000, e Porto Real, ${ }^{8}$ que entra neste grupo em 2002. Rio das Ostras fazia parte deste grupo até 2006, em 2008 cai para o grupo de renda média-alta.

A partir dos dados do agrupamento, foi calculada a matriz de intensidade de transição, estimada pelo método de máxima verossimilhança, com intervalos de $95 \%$ de confiança, apresentada na Tabela 3. O método possibilita estimar transições indiretas entre os estratos, o que soluciona o problema de subestimação das probabilidades de eventos.

O resultado apresenta uma matriz de intensidade de transição de máxima verossimilhança. As estimativas dos elementos da diagonal principal mostram sinal negativo, dado que são calculados por diferença das transições positivas de cada estrato, que indicam o risco instantâneo do município migrar de um estado para outro.

As maiores intensidades de transição concentram-se nas categorias vizinhas, o que indica que as migrações entre estratos de renda acontecem lentamente.

As intensidades são mais fortes nos estratos intermediários dois e três. Pode-se observar que as maiores probabilidades de transição acontecem do estrato dois para o um (16\%) e do três para o dois (17\%), ou seja, municípios que pioram a sua situação em relação ao estrato de renda no qual se encontram.

Após ajustar o modelo e obter a matriz de intensidade de transição, é possível obter a matriz de probabilidade de transição, que estabelece a probabilidade de determinado município transitar de um estrato para outro em um determinado tempo. Na matriz a seguir, apresentam-se as probabilidades de transição quando considerado o período total de tempo dividido em sete momentos.

Quando se consideram os seis momentos do tempo, vê-se que a diagonal principal só é fortemente dominante nos estados polares, quatro e um. Assim, a probabilidade de um município permanecer no grupo de renda baixa após os seis períodos considerados (que representam 12 anos) é de $64 \%$ e de $41 \%$ no caso dos municípios de renda alta. Isso significa que uma cidade que se encontra no estrato de renda média mais baixa ou no estrato de renda média mais alta tem maior probabilidade de permanecer nesse mesmo estado que de transitar para outro estrato.

No caso do primeiro grupo, como já foi dito, existem municípios que crescem, porém a um ritmo menor que os municípios que conformam o segundo estrato de renda e outros municípios que conformam o chamado "desastre econômico" (Quah 1993), que apresentam estancamento da renda ou crescimento negativo. A configuração regional desse grupo inclui todos os municípios do noroeste fluminense e a maioria dos municípios das regiões centro e metropolitana.

Assim, analisando o passar do tempo, é clara a configuração de grupos diferenciados de municípios, ou seja, municípios que se posicionam o suficientemente perto uns dos outros, distanciando-se de outros grupos de municípios.

\footnotetext{
${ }^{7} \mathrm{O}$ referido município apresenta diversificação mediana e especialização em setores industriais no período analisado.

${ }^{8} \mathrm{O}$ referido município apresenta diversificação mediana e especialização em setores industriais no período analisado.
} 


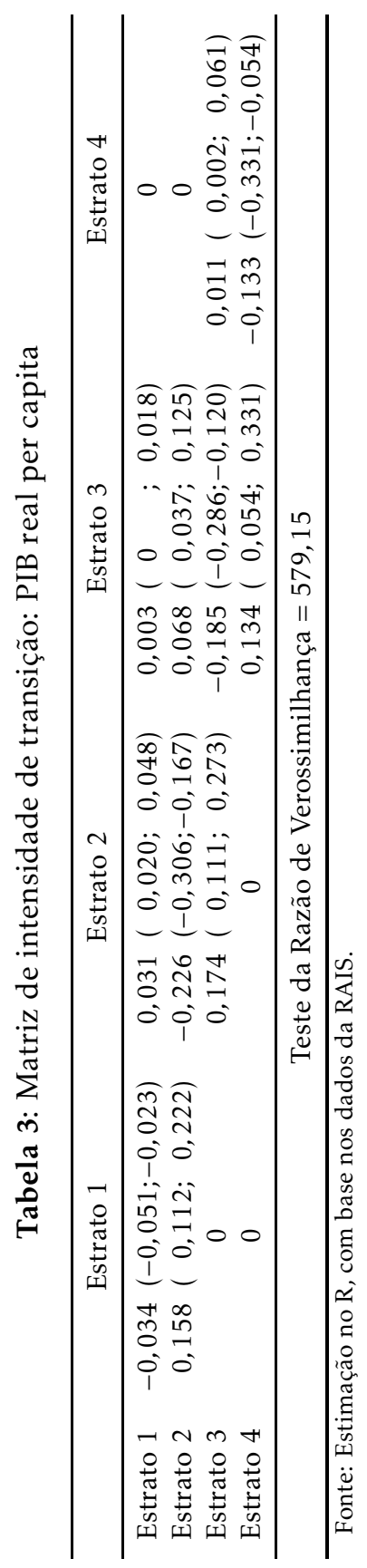


Tabela 4: Matriz de probabilidade de transição $t=7$

\begin{tabular}{lcccc}
\hline & Estrato 1 & Estrato 2 & Estrato 3 & Estrato 4 \\
\hline Estrato 1 & 0,640 & 0,304 & 0,048 & 0,008 \\
Estrato 2 & 0,461 & 0,448 & 0,076 & 0,015 \\
Estrato 3 & 0,168 & 0,301 & 0,411 & 0,120 \\
Estrato 4 & 0,064 & 0,166 & 0,356 & 0,414 \\
\hline
\end{tabular}

Fonte: Estimação no R, com base nos dados da RAIS.

\subsection{Agrupamento por rendimento do trabalho}

Os resultados do agrupamento por PIB per capita nos levam a perguntar o que acontece com o rendimento médio do trabalho, para tentar determinar se a situação é congruente com os estratos de renda ou se pode ser observado outro padrão de crescimento e estratificação em relação aos salários médios.

Diversos autores apontam a importância do mercado de trabalho, através do rendimento do trabalho, para explicar a diminuição da desigualdade no Brasil nas últimas décadas (Soares 2010).

No gráfico a seguir, apresentam-se as médias dos grupos ao longo do período analisado. Percebe-se que, ao longo do período analisado, existe um aumento real do rendimento médio para todos os grupos, o que mostra que o dinamismo em relação ao rendimento do trabalho é maior que no caso da renda.

A situação pode estar mostrando o que Soares (2010) encontra para o Brasil: boa parte da melhora na distribuição da renda se deve ao salário mínimo, contudo, a redução da desigualdade é também explicada por fatores que não são o piso salarial.

Um primeiro resultado interessante refere-se ao número de grupos encontrados. Na primeira parte do período analisado, nos anos 1996, 1998 e 2000, o critério de Calinski-Harabasz encontrou quatro grupos. Já para os anos dentro do período 2002-2010, o critério achou cinco grupos como número ótimo. Dessa forma, é clara a mudança de regime que acontece no período, com a conformação de mais um estrato de salário médio. Tal mudança no estado do Rio de Janeiro, a partir de 2002, coincide com o que Pochmann (2010) chama de novo padrão de mudança social no Brasil, que acontece a partir de $2003 \mathrm{e}$ tem como características fundamentais a combinação de expansão da renda e queda da desigualdade pessoal da renda.

$\mathrm{Na}$ Tabela 5, tem-se os resultados de frequência e média para os anos polares de amostra, 1996 e 2010. Nota-se uma mobilidade positiva importante entre os estratos de menor e maior rendimento médio do trabalho. Assim, o grupo de menor salário perde importância relativa à medida que transcorre o tempo, aumentando a frequência dos estratos de maior salário médio, os grupos três, quatro e cinco.

Os resultados são interessantes na medida em que se trata de municípios e sua posição relativa aos pares. Estimações de matrizes de transição têm uso comum em análises de microdados, como, por exemplo, Bosch \& Maloney (2010), a análise de municípios tem a peculiaridade de uma amostra substancialmente menor quando comparada às bases de microdados, o que poderia gerar problemas com as propriedades assintóticas dos estimadores utilizados. Esse nível de análise, porém, traz a vantagem de permitir verificar a relação 


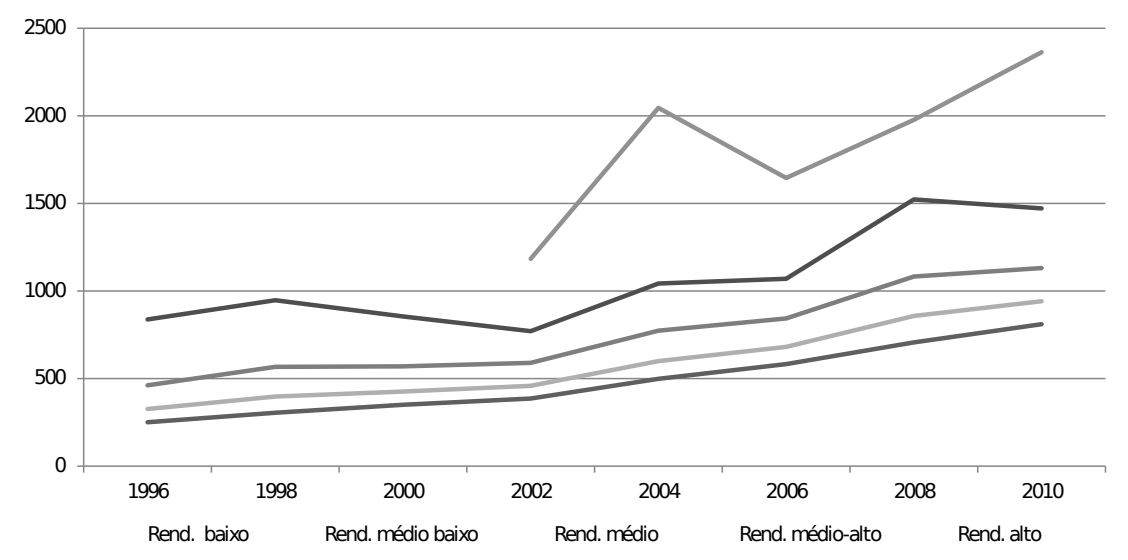

Fonte: Elaboração própria com base nos resultados do agrupamento

Figura 2: Rendimento médio do trabalho dos grupos de municípios 19962010

entre a estrutura produtiva e transições a novos regimes de crescimento das unidades amostrais, o que captura, de certa forma, variáveis não observáveis acerca dos múltiplos equilíbrios onde se encontram os municípios. O número de transições encontradas é bastante grande quando se considera a unidade amostral. Esse fenômeno evidencia a importância de se analisar a estrutura produtiva como potencial explicação para tal fenômeno. Parte-se das mudanças estruturais exógenas produzidas de forma importante a partir dos anos 2000 com a descoberta e exploração de grandes reservas de petróleo para analisar a relação entre a mudança estrutural e a evolução da renda e salários médios dos municípios.

Tabela 5: Conformação dos grupos de salário médio real dos municípios fluminenses 1996-2010

\begin{tabular}{lcccc}
\hline \multicolumn{2}{c}{1996} & & \multicolumn{2}{c}{2010} \\
\hline Grupo & $\begin{array}{l}\text { Salário médio } \\
\text { real }(\mathrm{R} \$)\end{array}$ & $\begin{array}{l}\text { Frequência } \\
\text { municípios) }\end{array}$ & $\begin{array}{l}\text { Salário médio } \\
\text { real }(\mathrm{R} \$)\end{array}$ & $\begin{array}{l}\text { Frequência }\left(\mathrm{n}^{\mathrm{o}}\right. \\
\text { municípios) }\end{array}$ \\
\hline Um & 251 & 37 & 811 & 22 \\
Dois & 326 & 24 & 941 & 32 \\
Três & 461 & 17 & 1131 & 25 \\
Quatro & 838 & 3 & 1471 & 9 \\
Cinco & - & - & 2363 & 5 \\
\hline
\end{tabular}

Fonte: Elaboração própria com base nos resultados do agrupamento.

Esse resultado para os municípios do Rio de Janeiro é congruente com o acontecido no Brasil. Pochmann (2010) mostra que, no período de 1997 a 2004 , o segmento de baixa renda abrangia $34 \%$ da população nacional, mas a partir de 2005 tal percentual passou a ser reduzido, representando, em 2008, $23 \%$ da população.

Na Tabela 6, apresenta-se a matriz de intensidade de transição para o caso do rendimento médio do trabalho. Como pode ser visto, as maiores intensidades de transição concentram-se nas categorias vizinhas, podendo-se prever 
que as migrações entre estratos salariais acontecem lentamente: não é de se esperar que o perfil salarial de uma cidade seja mudado com extrema rapidez.

A permanência (indicada de forma negativa) apresenta maiores intensidades que a migração entre estados. Isso significa que as cidades fluminenses, mesmo em um período de significativo dinamismo quanto aos aumentos do salário médio dos diferentes grupos, tendem a permanecer no mesmo estrato salarial. Em relação às transições, as maiores acontecem do estrato cinco para o quatro (30\%), do estrato um para o dois $(28 \%)$, do estrato três para o dois $(25 \%)$, do estrato quatro para o três $(17 \%)$, do dois para o três $(12 \%)$ e do quatro para o cinco (11\%).

Nesse caso, pode-se salientar que o aumento das médias dos salários em muitas cidades faz com que algumas delas não consigam sustentar a sua posição relativa, caindo para estratos de salários menores. Isso não necessariamente significa que tais cidades tenham uma queda do salário real médio ao longo do tempo, podendo manter ou ainda ter aumentado (menos que a média do estrato) o seu salário médio real.

$\mathrm{Na}$ matriz a seguir, apresentam-se as intensidades de transição quando considerado o total do período analisado (1996-2010) agrupadas em sete momentos.

Quando consideramos os sete momentos do tempo, vemos que a diagonal principal não é dominante. Por exemplo, a probabilidade de transição do estado um para o dois é maior que a probabilidade de permanecer no estado um, no total do período analisado (1996-2010). No estrato polar superior, é maior a probabilidade de migrar para o estado quatro (39\%) que de permanecer no estrato cinco (25\%).

Comparando os resultados das transições de rendimento do trabalho com aquelas da renda per capita, verifica-se uma mobilidade muito maior no caso salarial que no caso do PIB per capita. Esse resultado relaciona-se com a política salarial, uma vez que, no período, em especial desde 2002, teve-se um ganho real muito forte do salário mínimo, que é referencia dos rendimentos do trabalho de mais de 45 milhões de brasileiros (DIEESE 2010).

\subsection{Resultados: Modelo Probit ordenado}

O primeiro modelo estimado tem como variável dependente o estrato de renda ao qual o município pertence que assume valores ordenados de um até cinco, representando níveis ascendentes de renda real per capita.

Na Tabela 6, encontram-se os resultados para este modelo, aparecendo o resultado geral na primeira coluna e os efeitos marginais para cada um dos quatro grupos de renda, da segunda à quinta coluna. As probabilidades marginais foram calculadas para o município na média da amostra, o que significa que dizem respeito aos municípios que apresentam as variáveis explicativas num valor referente à média da amostra para cada um dos grupos.

Abaixo de cada variável estão os erros padrão associados a cada uma delas. Ressalta-se que, das variáveis explicativas, todas com exceção da distância da cidade à capital do estado, mostraram significância estatística, o que reforça a influência de variáveis associadas à estrutura produtiva para o incremento da renda e, consequentemente, a passagem a estratos superiores de renda per capita.

A atribuição de efeitos causais entre as variáveis deve ser evitada pela existência de endogeneidades não controladas na relação entre as variáveis 


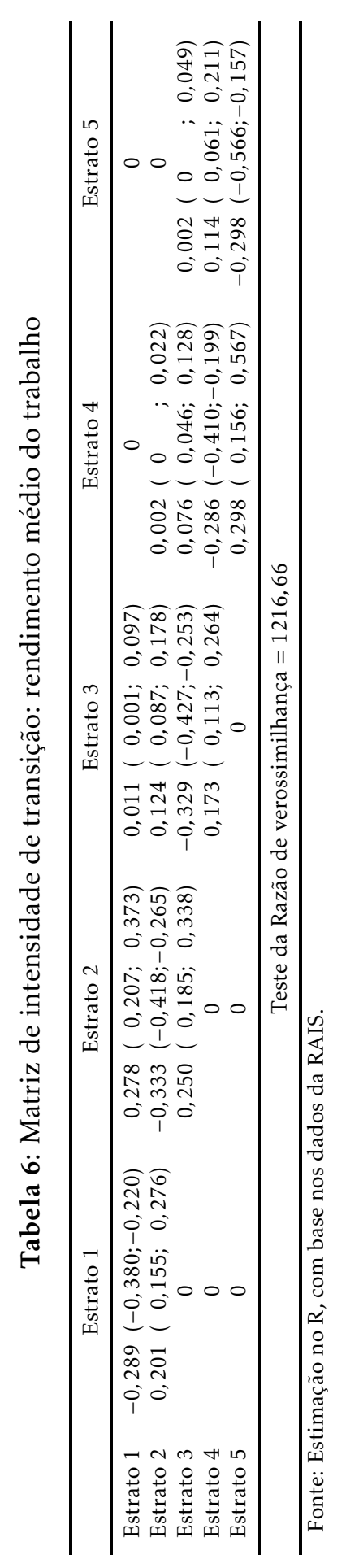


Tabela 7: Matriz de intensidade de transição $t=7$

\begin{tabular}{lccccc}
\hline & Estrato 1 & Estrato 2 & Estrato 3 & Estrato 4 & Estrato 5 \\
\hline Estrato 1 & 0,374 & 0,431 & 0,157 & 0,031 & 0,007 \\
Estrato 2 & 0,312 & 0,433 & 0,194 & 0,050 & 0,012 \\
Estrato 3 & 0,206 & 0,368 & 0,270 & 0,117 & 0,039 \\
Estrato 4 & 0,081 & 0,195 & 0,253 & 0,322 & 0,150 \\
Estrato 5 & 0,038 & 0,115 & 0,205 & 0,388 & 0,254 \\
\hline
\end{tabular}

Fonte: Estimação no R, com base nos dados da RAIS.

e mesmo simultaneidade na determinação destas. Tanto no caso de renda média quanto dos salários médios, é sempre questionável uma relação de causalidade unidirecional da variável educação. Podem existir variáveis não observáveis não incluídas no modelo que afetem simultaneamente os níveis de especialização e a renda dos municípios. No caso de rendimentos de trabalho, a existência de maior grau de especialização/diversificação ao interagir com a dinâmica do mercado de trabalho pode gerar forças centrípetas/centrífugas de acordo com o grau da mobilidade de mão de obra.

Destacam-se os seguintes efeitos:

- Com respeito ao tipo de especialização, a especialização em setor industrial (Esp. Ind.) contribui positivamente para as cidades fluminenses se posicionarem em grupos de renda superiores. Especializar-se em um setor industrial diminui a probabilidade de ficar no primeiro grupo de renda em $28 \%$ e fortalece a permanência das cidades nos estratos dois $(15 \%)$, três $(13 \%)$ e quatro $(0,4 \%)$. A especialização em atividades extrativas (Esp. Ext.) também influencia positivamente, porém a variável é não significativa ao nível de $10 \%$ de significância estatística.

- Em relação ao grau de especialização (QL), esta influencia positivamente a probabilidade de as cidades se posicionarem em estratos superiores de renda. O efeito marginal negativo no primeiro grupo implica que um aumento de $1 \%$ no QL diminui a probabilidade de permanecer no primeiro grupo em $2,1 \%$. O efeito marginal passa a ser positivo nos grupos de maior renda e, quando aumenta em $1 \%$ o QL, a probabilidade de permanecer nestes grupos aumenta em 1,2\% (grupo dois), 0,9\% (grupo três) e $0,1 \%$ (grupo quatro).

- O índice de diversificação relativa (IDR), que exibe o grau de diversificação da estrutura produtiva das cidades, mostrou-se positivo e significativo para permanecer em estratos de renda superiores. O efeito é maior que o das variáveis associadas à especialização produtiva, o que estaria indicando que uma estrutura produtiva diversificada, incluindo diversas atividades primárias, extrativas e industriais, favorece mais a transição e permanência em estratos superiores de renda, se comparada a uma estrutura especializada, mesmo sendo em algum dos setores da indústria. Um aumento de $1 \%$ no IDR diminui em $30 \%$ a probabilidade de permanecer no estrato de renda menor e aumenta a probabilidade de permanecer nos estratos dois (16\%), três $(13 \%)$ e quatro $(6 \%)$. 
Tabela 8: Resultado Modelo Probit (Geral) e efeitos marginais (EMg) por grupo (clu1-clu4)

\begin{tabular}{|c|c|c|c|c|c|}
\hline Variável & Geral & EMg clu1 & EMg clu2 & EMg clu3 & EMg clu4 \\
\hline Esp. Ind. & $\begin{array}{l}0,8475 \\
-0,1915\end{array}$ & $\begin{array}{l}-0,2877 \\
-0,0616\end{array}$ & $\begin{array}{l}0,1506 \\
-0,0359\end{array}$ & $\begin{array}{l}0,1326 \\
-0,0337\end{array}$ & $\begin{array}{l}0,0044 \\
-0,0003\end{array}$ \\
\hline Esp. Ext. & $\begin{array}{r}0,232 \\
-0,0369\end{array}$ & $\begin{array}{c}-0,0828 \\
-0,0070\end{array}$ & $\begin{array}{l}0,0430 \\
-0,0051\end{array}$ & $\begin{array}{l}0,0387 \\
-0,0031\end{array}$ & $\begin{array}{l}0,0012 \\
-0,0002\end{array}$ \\
\hline QL & $\begin{array}{l}0,0062 \\
-0,0017\end{array}$ & $\begin{array}{r}-0,0021 \\
-0,0006\end{array}$ & $\begin{array}{l}0,0012 \\
-0,0003\end{array}$ & $\begin{array}{l}0,0009 \\
-0,0003\end{array}$ & $\begin{array}{c}0,0001 \\
0\end{array}$ \\
\hline IDR & $\begin{array}{l}0,8530 \\
-0,2609\end{array}$ & $\begin{array}{r}-0,2942 \\
-0,0906\end{array}$ & $\begin{array}{l}0,1614 \\
-0,0544\end{array}$ & $\begin{array}{l}0,1294 \\
-0,0421\end{array}$ & $\begin{array}{l}0,0034 \\
-0,0224\end{array}$ \\
\hline Royalties & $\begin{array}{c}0,0007 \\
0\end{array}$ & $-0,0002$ & $\begin{array}{c}0,0001 \\
0\end{array}$ & $\begin{array}{c}0,0001 \\
0\end{array}$ & $\begin{array}{l}0 \\
0\end{array}$ \\
\hline Exportação & $\begin{array}{c}0,0001 \\
0\end{array}$ & $-0,0001$ & $\begin{array}{c}0,0001 \\
0\end{array}$ & $\begin{array}{c}0,0001 \\
0\end{array}$ & $\begin{array}{l}0 \\
0\end{array}$ \\
\hline Educ. Sup. & $\begin{array}{l}6,6449 \\
-1,6544\end{array}$ & $\begin{array}{r}-2,2921 \\
-0,5681\end{array}$ & $\begin{array}{l}1,2574 \\
-0,3555\end{array}$ & $\begin{array}{l}1,0081 \\
-0,2736\end{array}$ & $\begin{array}{l}0,0267 \\
-0,0021\end{array}$ \\
\hline Dist. à cap & $\begin{array}{l}0,0015^{*} \\
-0,0013\end{array}$ & $\begin{array}{c}-0,0005^{*} \\
-0,0004\end{array}$ & $\begin{array}{l}0,0003^{*} \\
-0,0002\end{array}$ & $\begin{array}{l}0,0002^{*} \\
-0,0002\end{array}$ & $\begin{array}{l}0 \\
0\end{array}$ \\
\hline Observações & 435 & $70,52 \%$ & $20,97 \%$ & $8,38 \%$ & $1,21 \%$ \\
\hline$L R c h i^{2}$ & 176,99 & & & & \\
\hline
\end{tabular}

- Em relação à participação no comércio exterior, exportar significa para as cidades uma maior probabilidade de se posicionar em estratos de renda maiores. O efeito é pequeno, mas positivo e significativo.

- A variável associada à qualidade do capital humano, relacionada com o percentual de trabalhadores com ensino superior, mostrou-se fortemente positiva para transitar e permanecer em estratos superiores

- Os royalties per capita apresentam sinal positivo e o coeficiente é significativo, porém a influência é pequena sobre as transições e sobre a permanência nos grupos superiores de renda. No caso do grupo de renda menor, um aumento de $1 \%$ nos royalties per capita diminui em $0,7 \%$ a probabilidade de permanecer no primeiro estrato de renda e aumenta a probabilidade de permanecer nos estratos superiores em $0,1 \%$. O fato de os municípios beneficiados com abundância de recursos de petróleo não responderem de forma significativamente diferente dos outros municípios corrobora evidências de outras pesquisas (Caselli \& Michaels 2009, Slaibe Postali \& Nishijma 2011).

A seguir, na Tabela 9, apresentam-se os resultados para o rendimento médio do trabalho como variável dependente. Nesse caso, todas as variáveis mostram coeficientes estatisticamente significativos.

As estimativas realizadas indicam os seguintes resultados:

- Em relação à estrutura produtiva, nota-se que o grau de especialização (QL) influencia positiva e significativamente a probabilidade de permanecer em estratos superiores de salário médio. Por sua vez, comparando o tipo de especialização, a especialização em atividades extrativas influencia mais fortemente que a especialização em setores industriais. 
- No caso da especialização na indústria, passar de uma especialização em setores primários para outra em indústria diminui a probabilidade de ficar no estrato salarial um em $13 \%$, dois em $2 \%$, e aumenta a probabilidade de ficar nos estratos três $(9 \%)$, quatro $(6 \%)$ e cinco $(0,7 \%)$. No caso da especialização em atividades extrativas, tem-se diminuição da probabilidade de $19 \%$ (estrato um), 10\% (dois), e aumento para permanecer nos estratos três (14\%), quatro $(13 \%)$ e cinco $(2 \%)$.

Tabela 9: Resultado Modelo Probit (Geral) e efeitos marginais (EMg) por grupo (clu1-clu5)

\begin{tabular}{lcccccc}
\hline Variável & Geral & EMg clu1 & EMg clu2 & EMg clu3 & EMg clu4 & EMg clu5 \\
\hline Esp. Ind. & 0,4499 & $-0,1343$ & $-0,0206$ & 0,0910 & 0,0573 & 0,0067 \\
& $-0,1292$ & $-0,0384$ & $-0,0122$ & $-0,0269$ & $-0,0181$ & $-0,0036$ \\
Esp. Ext. & 0,7867 & $-0,1926$ & $-0,1006$ & 0,1408 & 0,1303 & 0,0221 \\
QL & $-0,1590$ & $-0,0318$ & $-0,0351$ & $-0,0265$ & $-0,0356$ & $-0,0107$ \\
& 0,0036 & $-0,0011$ & $-0,0002$ & 0,0007 & 0,0005 & 0,0001 \\
IDR & $-0,0016$ & $-0,0005$ & $-0,0001$ & $-0,0003$ & $-0,0002$ & 0 \\
& 0,5233 & $-0,1585$ & $-0,0215$ & 0,1077 & 0,0651 & 0,0072 \\
Royalties & $-0,1651$ & $-0,0501$ & $-0,0144$ & $-0,0356$ & $-0,0224$ & $-0,0038$ \\
Exportação & 0,0003 & $-0,0001$ & $-0,0001$ & 0,0001 & 0 & 0 \\
Educ. Sup. & 0,0002 & $-0,0001$ & 0,0001 & 0,0001 & 0,0001 & 0 \\
Dist. à cap. & 0,5063 & $-2,5762$ & $-0,3501$ & 1,7511 & 1,0582 & 0,1169 \\
& $-1,2412$ & $-0,3857$ & $-0,2119$ & $-0,3197$ & $-0,0200$ & $-0,0517$ \\
\hline Observações & 435 & 0,0037 & 0,0002 & $-0,0008$ & $-0,0005$ & $-0,0001$ \\
\hline LRchi ${ }^{2}$ & $23,89 \%$ & $47,80 \%$ & $22,05 \%$ & $6,79 \%$ & $2,23 \%$ \\
\hline
\end{tabular}

Fonte: Estimação no Stata com base nos dados da RAIS, Ucam, IBGE.

- A diversificação produtiva (IDR) também favorece positivamente a permanência em estratos superiores em $11 \%$ (estrato três); $6 \%$ (estrato quatro) e $0,7 \%$ (estrato cinco). Ainda favorece a diminuição da probabilidade de permanecer nos estratos um (15\%) e dois (2\%). Por sua vez, o efeito sobre os salários médios é menor que no caso do efeito sobre a renda per capita.

- O recebimento de royalties de petróleo também influencia positiva e significativamente o rendimento médio do trabalho nas diferentes cidades. Porém, o efeito é menor que no caso do PIB per capita, ou seja, a relação é menos direta e, portanto, de menor intensidade. Cabe destacar que, dos cinco municípios que mais recebem compensações desse tipo per capita no período estudado (São João da Barra, Quissamã, Rio das Ostras, Carapebus, Parati, nessa ordem), nenhum se encontra no grupo de maior rendimento médio per capita e só um, Quissamã, pertencia ao grupo de alta renda per capita.

- Já as exportações, mesmo tendo um coeficiente pequeno, influenciam mais fortemente o salário médio que a renda per capita. Isso indicaria que aquelas cidades que apresentam uma estrutura produtiva mais exportadora favorecem a transição e permanência para níveis superiores de salário médio. 
- O tempo de estudo tem forte influência para a cidade aumentar a probabilidade de permanecer em grupos de maior salário médio. Logicamente, a variável tem um efeito maior que no caso do PIB per capita, dado que a influência estudo-salário é mais direta que no caso da renda média. Esse resultado estaria indicando que as capacidades formais são mais necessárias para manter ou aumentar o salário médio que no caso da renda. O efeito é especialmente forte para diminuir a probabilidade de permanecer no estrato um e para aumentar a probabilidade de permanecer nos estratos três e quatro. Diferenças no nível educacional são identificadas em outros trabalhos, como principais responsáveis pela desigualdade de rendimentos (Mendonça 1995, Cortez Reis et al. 2011).

- A distância à capital é a única variável que apresenta sinal negativo, o que é esperado, indicando que, quanto maior a distância da cidade em relação à capital, menor o salário médio da cidade em questão.

\section{Considerações finais}

O trabalho mediu o impacto do tipo de estrutura produtiva sobre a mobilidade relativa das cidades fluminenses, no período 1996-2010. Para refletir o tipo de estrutura produtiva de cada um dos municípios, foram utilizadas medidas de especialização e diversificação, além da magnitude da presença de royalties de petróleo e exportações para cada uma das cidades.

O exercício foi realizado usando duas estratégias empíricas: a dinâmica de transição entre estratos de renda e rendimentos do trabalho foi estimada valendo-se do método de cluster k-means, que permite conhecer o número de estratos, a conformação destes e sua evolução; e matrizes de transição de Markov, para conhecer a força das transições através do tempo.

Os resultados do agrupamento por renda per capita mostram duas claras tendências: um grupo pequeno de municípios que mantém ou melhora a sua posição relativa no estado do Rio de Janeiro e conforma grupos de renda média e alta e uma predominância de municípios pouco dinâmicos que permanecem no grupo de renda baixa.

$\mathrm{Na}$ análise de matriz de probabilidades de transição do PIB per capita, evidenciou-se que, ao longo do período 1996-2008, ocorreu um processo simultâneo de convergência e divergência. Em primeiro lugar, dentro dos estratos polares, em especial do estrato de baixa renda, existe um processo de aumento da proximidade entre os municípios. Em segundo lugar, é claro o distanciamento dos municípios dos estratos um e quatro, o que indica claramente a existência de divergência.

No que se refere à analise por rendimento do trabalho, a mobilidade dos municípios é maior, e essa mobilidade é positiva, dado que aumenta a participação dos grupos de maior rendimento médio. Porém, é clara a conformação de "clubes de rendimento", visto que, em lugar de encontrar um processo de convergência, mais um estrato foi formado ao longo do período.

O segundo estágio da pesquisa empírica exigia determinar como as características da estrutura produtiva da cidade influenciavam a probabilidade de transitar a estratos superiores de renda e rendimento do trabalho. Para isso, foi utilizado um modelo probit ordenado.

Os resultados indicam uma forte relação da estrutura produtiva com a dinâmica de transição dos municípios, quando consideramos o grau e tipo de 
especialização (QL) produtiva, ou seja, quando consideramos a diversificação da estrutura econômica do município (IDR). O IDR e o QL tem um efeito maior sobre a probabilidade de transitar a estratos superiores do PIB per capita que do o rendimento médio. Salienta-se que o efeito de uma estrutura produtiva diversificada é muito maior para transitar a estados superiores de renda e rendimento médio que no caso de uma forte especialização, em qualquer setor.

O efeito da especialização em setores da indústria está mais associado a transições entre grupos de PIB per capita que aqueles formados pelos salários. Por sua vez, a especialização em setores extrativos afeta mais o rendimento médio que o PIB per capita.

Com respeito aos royalties de petróleo, estes influenciam positiva e significativamente a transição a estados superiores de renda per capita e rendimento médio do trabalho, todavia com um efeito pequeno. Isso ressalta a importância do debate em torno da distribuição e controle de uso dessas importantes quantias. Olhar os resultados obtidos para a variável educação superior e sua importante influência na dinâmica transacional positiva pode ser um caminho para pensar em uma das formas de utilização de tais recursos.

Em síntese, pode-se dizer que existe, no período considerado, uma predominância de municípios fluminenses que não apresentam dinamismo, permanecendo no mesmo patamar de renda, e que aqueles que conseguem sair de estratos de renda baixa, o logram a partir de estruturas produtivas diversificadas e forte educação da mão de obra.

\section{Referências Bibliográficas}

Abdel-Rahmany, H. \& Anas, A. (2004), Theories of systems of cities, Handbook of Regional and Urban Economics, Amsterdam, Elsevier.

Abdel-Rahmany, H. \& Fujita, M. (2006), 'Product variety, marshallian externalities and city sizes?', Journal of Regional Science 30(2).

Aghion, P. \& Howitt, P. (1997), The Economics of Growth, Cambridge: MIT Press.

Anas, A. \& Xiong, K. (2003), 'Intercity trade and the industrial diversification of cities', Journal of Urban Economics 54(2).

Andrade, E., Laurini, M., Madalozzo, R. \& Valls Pereira, P. L. (2004), 'Convergence clubs among brazilian municipalities', Economics Letters 83(2), 179184.

Azzoni, C., Menezes Filho, N., Menezes, T. A. \& Silveira Neto, R. M. (2004), 'Geography and income growth across brazilian states: evidence from cohort data', Journal of Regional Science .

Barro, R. \& Sala-I-Martin, X. (1990), Economic growth and convergence across the united states, Technical report, NBER.

Barro, R. \& Sala-I-Martin, X. (1992), 'Convergence', Journal of Political Economy (100), 223-251. 
Bosch, M. \& Maloney, W. (2010), 'Comparative analysis of labor market dynamics using markov processes: An application to informality', Labor Economics 17(4), 621-631.

Britto, J. \& Albuquerque, E. M. (2002), 'Clusters industriais na economia brasileira: uma análise exploratória a partir de dados da rais', Estudos Econômicos 32(1), 71-102.

Calinski, T. \& Harabasz, J. (1974), 'A dendrite method for cluster analysis', Communications in Statistics 1(3), 1-27.

Caselli, F. \& Michaels, G. (2009), Do oil windfall improve living standards? evidence from brazil, Working Paper 15550, NBER.

Catela, E. Y., Gonçalves, F. \& Porcile, G. (2010), 'Municipios brasileños: economias de aglomeración y niveles de desarrollo en 1997 y 2007', Revista Cepal (101), 145-161.

Cortez Reis, M., Pinto Ambrozio, A. \& Machado, D. (2011), 'Uma análise da relação entre tecnologia no local de trabalho e rendimentos no brasil', Economia Aplicada 15(3), 459-483.

Crocco, M. A., Galinari, R., Santos, F., Borges Lemos, M. \& Simões, R. (2006), 'Metodologia de identificação de aglomerações produtivas locais', Nova Economia 16(2), 211-241.

DIEESE (2010), Política de valorização do salário mínimo, Nota Técnica 86, Departamento Intersindical de Estatística e Estudos Socioeconômicos.

Durlauf, S. N. \& Johnson, P. A. (1995), 'Multiple regimes and cross-country growth behavior', Journal of Applied Econometrics (10), 365-384.

Frühwrth-Schnatter, S. (2006), Finite Mixture and Markov Switching Models?, Springer.

Fujita, M. (1999), 'Location and space-economy at half a century: Revisiting professor isard's dream on the general theory', The Annals of Regional Science 33(4), 371-381.

Fujita, M., Krugman, P. \& Venables, A. J. (2001), The Spatial Economy: Cities, Regions, and International Trade, MIT Press.

Galinari, R., Crocco, M. A., Borges Lemos, M. \& Basques, M. F. D. (2007), 'O efeito de aglomeração sobre os salários industriais: uma aplicação ao caso brasileiro?', Revista de Economia Contemporânea 11(3).

Gondim, J. L. B. \& Barreto, F. A. (2004), O uso do núcleo estocástico para identificação de clubes de convergência entre estados e municípios brasileiros, in 'Anais do XXXII Encontro Nacional de Economia - ANPEC'.

Henderson, J. V. (1974), 'The sizes and types of cities', American Economic Review 64(4).

Henderson, J. V. (1986), 'Efficiency of resource usage and city size', Journal of Urban Economics 19(1). 
Henderson, J. V., Kuncoro, A. \& Turner, M. (1995), 'Industrial development in cities', Journal of Political Economy 103(5).

Kabfleisch, J. D. \& Lawless, J. F. (1985), 'The analysis of panel data under a markov assumption', Journal of the American Statistical Association (80), 863871.

Krugman, P. (1991), 'Increasing returns and economic geography', Journal of Political Economy 99(3).

Laurini, M., Andrade, E. \& Pereira, P. L. V. (2003), Clubes de convergência de renda para os municípios brasileiros: Uma análise não-paramétrica, in 'Anais do Encontro brasileiro de econometria - SBE'.

Lucas, R. (1988), 'On the mechanics of economic development', Journal of Monetary Economics 22, 3-42.

Magalhães, J. C. R. \& Miranda, R. (2009), 'Dinâmica da renda per capita, longevidade e educação nos municípios brasileiros', Estudos Econômicos 39(3), 539-569.

Mankiw, N., Romer, D. \& Weil, D. (1992), 'A contribution to the empirics of economic growth', Quartely Journal of Economics 107, 207-237.

Mendonça, R. P. B. (1995), Bem-estar, pobreza e desigualdade de renda: uma avaliação da evolução histórica e das disparidades regionais, Textos para discussão, IPEA.

Pochmann, M. (2010), 'Estrutura social no brasil: mudanças recentes', Serviço Social e Sociedade (104), 637-649.

Puga, D. (2010), 'The magnitude and causes of agglomeration economies', Journal of Regional Science 50(1), 203-219.

Quah, D. (1997), Empirics for growth and distribution: Stratification, polarization, and convergence clubs, C.E.P.R. Discussion Papers 1586, CEPR.

Quah, D. T. (1993), 'Empirical cross-section dynamics in economic growth', European Economic Review (37), 426-434.

Quigley, J. (1998), 'Urban diversity and economic growth', Journal of Economic Perspectives 12(2).

Rivera-Batiz, F. L. (1988), 'Increasing returns, monopolistic competition and agglomeration economies in consumption and production', Regional Science and Urban Economics 18(1).

Romer, P. (1986), 'Increasing returns and long run growth', Journal of Political Economy 94, 1002-1037.

Rosenthal, S. \& Strange, W. (2003), 'Geography, industrial organization, and agglomeration', The Review of Economics and Statistics 85(2).

Slaibe Postali, F. A. \& Nishijma, M. (2011), 'Distribuição das rendas do petróleo e indicadores de desenvolvimento municipal no brasil nos anos 2000s', Estudos Econômicos 41(2), 463-485. 
Soares, S. (2010), A distribuição dos rendimentos do trabalho e a queda da desigualdade de 1995 a 2009, Nota técnica 45, IPEA.

Solow, R. M. (1956), 'A contribution to the theory of economic growth', Quarterly Journal of Economics 70(1), 65-94.

Wheaton, W. \& Lewis, M. (2002), 'Urban wages and labor market agglomeration', Journal of Urban Economics 51(3). 


\section{Apêndice $A$}

Tabela A.1: Divisões da Seção C, CNAE 2.0

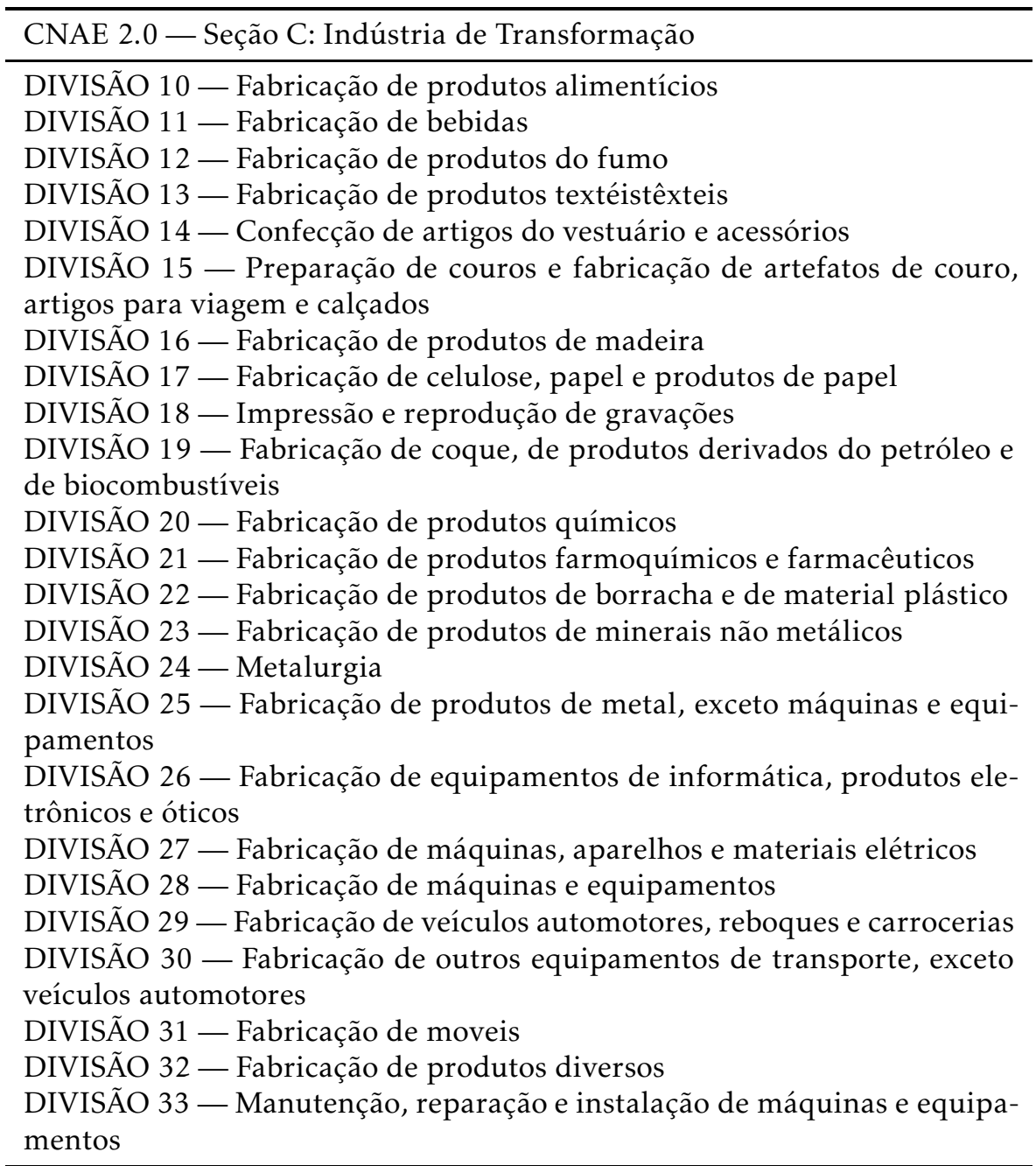

Fonte: Resoluções CONCLA, 2007. 


\section{Apêndice B}

Tabela B.1: Cluster inicial (1998) e final (2008) de cada município

\begin{tabular}{lcc}
\hline Município & Cluster inicial & Cluster final \\
\hline Armação dos Búzios & 3 & 3 \\
Cantagalo & 3 & 1 \\
Itatiaia & 3 & 1 \\
Angra dos Reis & 3 & 2 \\
Carapebus & 3 & 2 \\
Itaguaí & 3 & 2 \\
Piraí & 3 & 2 \\
Resende & 3 & 2 \\
Rio de Janeiro & 3 & 2 \\
Volta Redonda & 3 & 2 \\
São João da Barra & 1 & 3 \\
Aperibé & 1 & 1 \\
Araruama & 1 & 1 \\
Barra do Piraí & 1 & 1 \\
Belford Roxo & 1 & 1 \\
Bom Jardim & 1 & 1 \\
Bom Jesus do Itabapoana & 1 & 1 \\
Cachoeiras de Macacu & 1 & 1 \\
Cambuci & 1 & 1 \\
Cardoso Moreira & 1 & 1 \\
Conceição de Macabu & 1 & 1 \\
Cordeiro & 1 & 1 \\
Duas Barras & 1 & 1 \\
Engenheiro Paulo de Frontin & 1 & 1 \\
Guapimirim & 1 & 1 \\
Itaboraí & 1 & 1 \\
Italva & 1 & 1 \\
Japeri & 1 & 1 \\
Laje do Muriaé & 1 & 1 \\
Macuco & 1 & 1 \\
Magé & 1 & 1 \\
Maricá & 1 & 1 \\
Mendes & 1 & 1 \\
Miracema & 1 & 1 \\
Natividade & 1 & 1 \\
Nova Iguaçu & 1 & 1 \\
\hline Fono & 1 \\
\hline
\end{tabular}

Fonte: Elaboração própria. 
Tabela B.2: Cluster inicial (1998) e final (2008) de cada município

\begin{tabular}{|c|c|c|}
\hline Município & Cluster inicial & Cluster final \\
\hline Paracambi & 1 & 1 \\
\hline Parati & 1 & 1 \\
\hline Paraíba do Sul & 1 & 1 \\
\hline Paty do Alferes & 1 & 1 \\
\hline Pinheiral & 1 & 1 \\
\hline Porciúncula & 1 & 1 \\
\hline Quatis & 1 & 1 \\
\hline Queimados & 1 & 1 \\
\hline Rio Bonito & 1 & 1 \\
\hline Rio Claro & 1 & 1 \\
\hline Santa Maria Madalena & 1 & 1 \\
\hline Santo Antônio de Pádua & 1 & 1 \\
\hline Saquarema & 1 & 1 \\
\hline Seropédica & 1 & 1 \\
\hline Silva Jardim & 1 & 1 \\
\hline Sumidouro & 1 & 1 \\
\hline São Fidélis & 1 & 1 \\
\hline São Francisco de Itabapoana & 1 & 1 \\
\hline São Gonçalo & 1 & 1 \\
\hline São José de Ubá & 1 & 1 \\
\hline São José do Vale do Rio Preto & 1 & 1 \\
\hline São João de Meriti & 1 & 1 \\
\hline São Pedro da Aldeia & 1 & 1 \\
\hline São Sebastião do Alto & 1 & 1 \\
\hline Tanguá & 1 & 1 \\
\hline Trajano de Morais & 1 & 1 \\
\hline Valença & 1 & 1 \\
\hline Varre-Sai & 1 & 1 \\
\hline Rio das Flores & 1 & 2 \\
\hline Campos dos Goytacazes & 2 & 3 \\
\hline Areal & 2 & 1 \\
\hline Arraial do Cabo & 2 & 1 \\
\hline Barra Mansa & 2 & 1 \\
\hline Carmo & 2 & 1 \\
\hline Comendador Levy Gasparian & 2 & 1 \\
\hline Iguaba Grande & 2 & 1 \\
\hline Itaocara & 2 & 1 \\
\hline Itaperuna & 2 & 1 \\
\hline Mangaratiba & 2 & 1 \\
\hline Miguel Pereira & 2 & 1 \\
\hline Niterói & 2 & 1 \\
\hline Nova Friburgo & 2 & 1 \\
\hline Petrópolis & 2 & 1 \\
\hline Sapucaia & 2 & 1 \\
\hline
\end{tabular}

Fonte: Elaboração própria. 
Tabela B.3: Cluster inicial (1998) e final (2008) de cada município

\begin{tabular}{lcc}
\hline Município & Cluster inicial & Cluster final \\
\hline Teresópolis & 2 & 1 \\
Três Rios & 2 & 1 \\
Vassouras & 2 & 1 \\
Cabo Frio & 2 & 2 \\
Casimiro de Abreu & 2 & 2 \\
Duque de Caxias & 2 & 2 \\
Macaé & 2 & 2 \\
Rio das Ostras & 4 & 3 \\
Porto Real & 4 & 4 \\
Quissamã & 4 & 4 \\
Mesquita & - & 1 \\
\hline
\end{tabular}

Fonte: Elaboração própria. 


\section{Apêndice C Metodologia}

\section{C.1 Cluster k-means}

O objetivo da utilização do modelo de cluster $k$-means neste trabalho responde à necessidade de determinar:

a) O número de estratos de renda e de rendimento do trabalho que existe entre os municípios fluminenses, sem ter que realizar uma divisão arbitrária entre estes regimes;

b) As médias e desvios padrão destes estratos, assim como o número de municípios que os compõem;

c) A evolução temporal dos estratos e dos seus componentes.

A análise de cluster visa identificar algumas características específicas dos componentes homogêneos dentro da uma população heterogênea, através de grupos a partir de dados univariados ou multivariados.

A análise de cluster consiste em dois passos: a) selecionar o algoritmo para agrupar os dados; e b) selecionar um critério para escolher o número ótimo de grupos. Quanto ao primeiro ponto, utiliza-se o método $k$-means que é um algoritmo de agrupamento particional proposto por MacQueen em 1967, valendose de uma técnica não hierárquica que tem como intuito agrupar elementos por meio de um processo mais flexível, no sentido de que um item alocado inicialmente em um grupo pode ser realocado diversas vezes durante o andamento do processo de agrupamento.

Em termos precisos, o algoritmo $k$-means objetiva, a partir de um conjunto de $n$ pontos, pontos em $R^{d}$ que minimizem a distância média quadrada de cada ponto ao centroide do conjunto mais próximo.

Para formar os grupos, o algoritmo agrupa elementos de acordo com a sua proximidade, obedecendo duas premissas: obter máxima similaridade entre os elementos do mesmo conglomerado e máxima dissimilaridade entre os conglomerados diferentes. Para selecionar o número mais adequado de clusters dentro da técnica de $k$-means a partir da matriz de dados dos atributos de um objeto, propõe-se o modelo de seleção heurística de Calinski \& Harabasz (1974), que consiste em dois passos:

1. Para todas as soluções de cluster entre as que se quer escolher, determinar o valor do índice $\mathrm{CH}$.

2. Selecionar a solução com o maior índice $\mathrm{CH}$.

\section{C.2 Modelos multi-estados ou de regimes múltiplos 9}

O objetivo da utilização do modelo multi estados neste trabalho responde à necessidade de determinar:

a) As transições entre estratos de renda e de rendimentos do trabalho dos municípios fluminenses;

\footnotetext{
${ }^{9}$ Esta seção foi construída a partir de Frühwrth-Schnatter (2006).
} 
b) As probabilidades destas transições, que se assumem diferenciadas segundo o estrato.

Um processo multi estado é um processo estocástico $\{S(t), t \in[0, \infty)\}$ em que $S(t)$ é uma variável aleatória que assume valores no conjunto de estados $\Gamma=\{1, \ldots, H\}$. O processo é caracterizado pela matriz de probabilidades de transição que representando a probabilidade de uma unidade se encontrar em certo estado em cada momento do tempo. Uma restrição que devemos considerar na matriz de probabilidade de transição é que cada linha da matriz tem soma igual a um, isto é, $\sum_{j} P_{h j}(s, t)=1$, em que representa a probabilidade de um indivíduo se encontrar no estado $j$ no tempo $t$, dado que ele estava no estado $n$ no instante $s$, com $s \leq t$ e $h, j=1, \ldots, H$.

A dinâmica das transições entre estratos pode ser descrita como uma matriz de transição que contém a probabilidade de permanecer em um dado estado e as probabilidades de mover-se para outro estrato. As intensidades dependem no tempo do processo $t$, ou em termos gerais, de um conjunto de variáveis explicativas específicas de todas as unidades estudadas que mudam ao longo do tempo.

A intensidade de transição representa a probabilidade instantânea da mudança do estado $r$ para o estado $s$ :

$$
q_{r s}(t, z(t))=\lim _{\delta t \rightarrow 0} \frac{P\left(S(t+\delta t)=\frac{s}{S(t)}=r\right)}{\delta t}
$$

A partir das intensidades, pode se formar a matriz $\wedge$, cujas linhas somam zero e na qual as entradas da diagonal são definidas por $q_{r r}=-\sum_{s \neq r} q_{r s}$ :

$$
\wedge=\left(\begin{array}{lll}
q_{11} & q_{12} & q_{13} \\
q_{21} & q_{22} & q_{23} \\
q_{31} & q_{32} & q_{33}
\end{array}\right)
$$

Para estimar um modelo de estados múltiplos, estima-se a matriz de intensidade de transição, considerando o modelo de Markov. Um processo estocástico $\{S(t), t \in[0, \infty)\}$ é um processo markoviano se, para quaisquer $T_{0}<T_{1}<$ $\ldots<T_{i}<T_{j}$ e quaisquer inteiros $k_{0}, K_{1}, \ldots, k_{j}$,

$$
P\left\{S\left(T_{j}\right)=\frac{k_{j}}{S\left(T_{0}\right)}=k_{0}, S\left(T_{1}\right)=k_{1}, \ldots, S\left(T_{j-1}\right)=k_{j-1}\right\}=P\left\{S\left(T_{j}\right)=\frac{k_{j}}{s\left(T_{j-1}\right)}=k_{j-1}\right\}
$$

A hipótese fundamental do modelo de Markov é que a evolução futura depende apenas do estado corrente no qual a unidade encontra-se. Isto é, $q_{r s}\left(t, z(t), F_{t}\right)$ é independente de $F_{t}$, onde $F_{t}$ é a observação histórica do processo anterior ao momento $t$.

Num modelo de Markov contínuo no tempo, um período no estado $\mathrm{r}$ terá uma distribuição exponencial, com taxa dada por $-q_{r r}$, (ou média $-\frac{1}{q_{r r}}$ ). Os elementos restantes da linha $r$ de $Q$ são proporcionais às probabilidades que governam o próximo estado depois de $r$ para o qual as unidades fazem a transição. A probabilidade de que uma unidade ocupe o estado $s$ imediatamente depois do estado $r$ é $-\frac{q_{r s}}{q_{r r}}$.

A propriedade markoviana (5) implica importantes relações entre as probabilidades de transição $P_{h j}$. Se fixarmos um ponto $\xi$ no intervalo [s,t], tal que 
$s<\xi<t$, e consideramos as respectivas variáveis aleatórias $S(s), S(\xi), S(t)$, então,

$$
P_{h j}(s, t)=\sum_{i} P_{h i}(s, \xi) P_{i j}(\xi, t)
$$

com $h, j=1,2, \ldots$ e $s<\xi<t$.

Kabfleisch \& Lawless (1985) descrevem um método geral para avaliar a probabilidade de um modelo de estados múltiplos aplicável a qualquer forma de matriz de transição, a partir da informação de estados observados em distintos momentos do tempo.

A relação entre a matriz de probabilidade de transição $P(s, t)$ e a matriz de intensidade de transição $\wedge(t)$ é dada pelas equações diferenciais de Kolmogorov,

$$
\frac{\partial}{\partial t} P(s, t)=P(s, t) \wedge(t) P_{h j}(0, t)=P[S(t)=\operatorname{fracj} S(s)=h]
$$

As probabilidades de transição são as soluções para as equações diferenciais em (7), considerando que $\wedge(t)$ é não homogênea, ou seja, não é constante em relação ao tempo. Quando todas as unidades da população alvo têm a mesma intensidade de transição, diz-se que a população é homogênea. Entretanto, se consideramos uma população heterogênea é razoável dividi-la em subgrupos de forma que a homogeneidade seja obtida.

O teste da razão de verossimilhança (LR) é utilizado para comparar o modelo com restrição e sem restrição, nos quais é calculado o valor da função de verossimilhança no ponto máximo de cada um. O teste é distribuído assintoticamente como uma chi-quadrado com $g$ graus de liberdade (onde $g$ é o número de restrições). Se o valor da estatística for maior que o valor crítico ao nível de significância desejado rejeita-se a hipótese nula.

\section{C.3 Modelo Probit Ordenado}

O objetivo da utilização do modelo probit ordenado neste trabalho responde à necessidade de:

a) Encontrar a probabilidade de que os municípios fluminenses se encontrem em determinados estratos de renda/salários, considerando que a variável dependente é categórica, isto é, cai em diferentes categorias mutuamente excludentes (níveis de renda e de salário médio) e estas categorias podem ser ordenadas (de menor a maior renda e salário médio).

b) Mostrar que essa probabilidade depende de certas variáveis associadas às características da estrutura produtiva da cidade.

O probit ordenando considera que a variável latente cruza limiares de renda ou salário médio, progressivamente superiores. Para o município individual $i$, temos:

$$
y_{i}^{*}=x_{i} \beta+u_{i}
$$

A variável latente $y_{i}^{*}$ é ordenada por níveis de renda e salário médio, selecionados a partir do modelo de cluster. Para um modelo ordenado de $m$ alternativas, define-se: 


$$
y_{i}=j \sec \alpha_{j-1}<y_{i}^{*} \leq \alpha_{j}, j=1, \ldots, m
$$

Logo,

$$
\begin{aligned}
\operatorname{Pr}\left(y_{i}=j\right) & =\operatorname{Pr}\left(\alpha_{i}<y_{i}^{*} \leq \alpha_{j}\right) \\
& =\operatorname{Pr}\left(\alpha_{j-1}<x_{i} \beta+u_{i} \leq \alpha_{j}\right) \\
& =\operatorname{Pr}\left(\alpha_{j-1}-x_{i}^{\prime} \beta<u_{i} \leq \alpha_{j} x_{i}^{\prime} \beta\right) \\
& =F\left(\alpha_{j}-x_{i}^{\prime} \beta\right)-F\left(\alpha_{j-1}-x_{i}^{\prime} \beta\right)
\end{aligned}
$$

onde $F$ é a função de distribuição cumulativa de $u_{i}$. Os parâmetros da regressão $\beta$ e $\alpha_{j}$, os $m-1$ parâmetros threshold, são obtidos maximizando o logaritmo da função de verossimilhança com $p_{i j}=\operatorname{Pr}\left(y_{i}=j\right)$ como definido acima. As propriedades dos estimadores de máxima verossimilhança do modelo são consistentes, assintoticamente normais e assintoticamente eficientes.

Para o modelo probit ordenado, $u$ é distribuído normalmente com $F()=$. $\Phi($.$) , a função de distribuição de cumulatividade normal padrão.$ 